\title{
EL TEATRO DE GÉNERO CHICO EN BUENOS AIRES EN LOS AÑOS '20, UNA MIRADA DE CONJUNTO DESDE LA HISTORIA SOCIAL
}

El trabajo analiza el movimiento teatral porteño de los años '20 a partir de una perspectiva de historia social. Se argumenta en qué sentido este teatro fue una experiencia social particular pero característica de la vida urbana porteña de los años '20, en tanto fue condicionada y condicionante de las transformaciones que experimentaba la ciudad. Para esto, se recrean los principales rasgos de la sociedad porteña de esos años para luego presentar y relacionar diversos rasgos del mundo del teatro con las transformaciones de la sociedad.

Palabras claves: Buenos Aires, teatro, experiencias sociales.

\section{Abstract}

This paper analyses the theatrical movement in Buenos Aires during the 20's based on a social history perspective.

It discusses in which sense this theatre was a particular social experience but also typical of the porteña urban life in the 20 's, since it was both conditioned by and a condition for the transformations suffered by the city during those days. In order to do so, this work recreates the most important characteristics of the society back then, and then presents and relates the characteristics of the theatre world with the transformations of the society.

Keywords: Buenos Aires, theatre, social experience. 


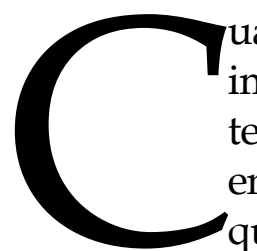

uando Augusto Alvarez, importante empresario teatral de Buenos Aires, se enteró de las condiciones que su emisario en Francia había aceptado de parte del popular chansonier Maurice Chevalier para viajar al Río de la Plata, creyó que todo su negocio se vendría abajo. Además de un oneroso contrato, el francés pedía actuar sólo en una función diaria, reclamaba su derecho de rechazar los espectáculos en los que fuera a participar si no eran de su agrado y solicitaba una serie de comodidades para su camarín.

Corría el año 1925: el teatro de revista corte francés se consolidaba en las principales capitales del mundo y Alvarez apostaba a que la contratación de Chevalier, artista que brillaba en los escenarios franceses, permitiría que uno de sus teatros, el Porteño, se afianzara definitivamente en una plaza que se volvía cada vez más competitiva. Por eso, pese a las exigencias del artista, Alvarez decidió seguir adelante con el proyecto.

Chevalier y su compañera Ivonne Valée llegaron a Buenos Aires a mediados de mayo de 1925; la frialdad con que el artista saludó a sus anfitriones no hizo sino confirmar las dificultades ya avizoradas en

la negociación del contrato. Luego de instalarse en el Plaza Hotel -uno de los más lujosos del momento-, concurrió al Porteño y presenció el ensayo de la obra que lo tendría como protagonista. Recorrió las instalaciones del teatro y observó su camarín. Su conclusión fue tajante y así lo recordó el mismo Álvarez en sus memorias: "querido amigo.... todo esto no va conmigo" -le dijo- "Mierda con vuestro sucio teatro.

1 Doctora en Historia, por la Universidad de Buenos Aires (UBA). Actualmente, becaria de posdoctorado del Consejo Nacional de Investigaciones Científicas y Tecnológicas (CONICET), investigadora del Instituto de Investigaciones en Historia Argentina y Americana Emilio Ravignani, de la Facultad de Filosofía y Letras de la UBA e investigadora en el Centro de Estudios en Historia Política de la Universidad de San Martín. Coordinadora del Programa de Investigación "Mercado de espectáculos, industrias del entretenimiento y consumos culturales. Buenos Aires, siglo XX." Centro de Estudios de Historia Política. UNSAM: 2010. Docente de la materia Historia Social General, en la Facultad de Filosofía y Letras de la UBA y docente de la materia Problemas de Historia Argentina, en la Universidad Nacional Arturo Jauretche.
No cuenten conmigo. Regreso a París. Mi contrato me da todo el derecho. Hasta nunca" (MANFREDI, 1989, p. 75).

Toda la inversión parecía deshacerse, pero Alvarez y sus colaboradores- Bayón Herrera, Manuel Romero e Ivo Pelay -autores y directores teatrales de conocida trayectoria en la escena porteña-, no se dieron por vencidos. Decidieron que harían la obra de todos modos: en lugar del francés, actuaría el actor Marcelo Ruggero, quien imitaría en tono de parodia al mismo Chevalier.

Ocurrió entonces que mientras Manuel Romero dirigía el ensayo de la obra ya modificada, Chevalier volvió al teatro y miró las escenas sentado en una platea.... y rió a más no poder con la actuación de Ruggero. Pocos días después, el gran chansonier debutó en el escenario del Porteño, aceptó su pequeño camarín y trabajó en las cuatro secciones en las que se ofrecía el espectáculo, incluidas las matinés de los domingos y feriados. La temporada de 1925 del Porteño fue un éxito.

La visita de Chevalier ha sido resaltada en varias oportunidades a fin de mostrar el atractivo que comenzaba a tener Buenos Aires como plaza para los espectáculos de revista (PUJOL, 1994). No obstante, la anécdota invita a indagar acerca de las características del mundo teatral porteño de esos años. Si bien esta cuestión no está ausente en los estudios sobre historia del teatro argentino, lo cierto es que en esa literatura ese interrogante ha sido puesto en relación a problemas del desarrollo estético y dramático, a cuestiones vinculadas a la figura de diversos autores o actores, e incluso a la construcción de un relato más general sobre la historia del teatro nacional. ${ }^{2}$ Por un lado, en las fuentes de los años '20 se hablaba de "teatro de género chico" para dar cuenta de aquellas obras cortas, desarrolladas en uno, dos o tres actos, con personajes caricaturizados, conflictos sencillos, etc que se ofrecían en los teatros por secciones. El repertorio incluía tipo de obras tales como comedias,

2 Ver bibliografía citada al final. 
pochades, juguetes, vodeviles, sainetes e incluso revistas. A su vez, se hablaba de "género chico" en contraposición al teatro de "género grande", el cual incluía a la ópera y al repertorio universal. Por su parte, los estudios del teatro han puesto en relación parte de estas características con el hecho de que, al ser requeridas para un circuito comercial, las obritas del género chico perdieron poco a poco perdieron su valor estético, tendieron a repetir temas y personajes y apuntaron sólo a conseguir la risa y el aplauso del público como contraparte de las ganancias empresariales. Concluyeron así que los años '20 constituyeron una etapa de cierta decadencia para la dramaturgia nacional.

Partiendo de los aportes realizados por esos estudios pero tomando distancia de cualquier valoración estética o vinculada a la evolución del teatro nacional, el siguiente trabajo propone poner foco sobre el movimiento teatral porteño de los años '20, en especial en el teatro llamado en las fuentes como de "género chico" a partir de una perspectiva de historia social. Se busca argumentar en qué sentido este teatro fue una experiencia social particular pero característica de la vida urbana porteña de los años '20, en tanto fue condicionada y condicionante de las transformaciones que experimentaba la ciudad. Se propone, en definitiva, explicar de qué se trataba ese mundo del teatro en relación con las experiencias de la sociedad. En este sentido, la línea de reflexión propuesta se apoya y busca dialogar con aquella producción historiográfica que ha estudiado, tanto para el caso porteño como para otros contextos, las experiencias sociales implicadas en la producción, circulación y consumo de productos culturales. ${ }^{3}$

3 GONZALEZ VELASCO. Carolina. Gente de Teatro: género chico y sociedad. Buenos Aires, en los años '20. Buenos Aires: Siglo XXI. (en prensa). Para los años '20 y '30 en Buenos Aires Véase: SARLO, Beatriz. El Imperio de los Sentimientos. Buenos Aires: Catálogo Editora, 1985 sobre las novelas románticas semanales; KARUSH, Matthew. The Melodramatic Nation: Integration and Polarization in the Argentine Cinema of the 1930s en Hispanic American Historical Review, 2007, sobre el cine y el género del melodrama en relación a la construcción de imágenes de la nación y la clase; FRYDEMBERG, Julio.
El texto recrea los principales rasgos de la sociedad porteña de los años '20 para adentrarse luego en la presentación y análisis de diversos rasgos del mundo del teatro en relación con las transformaciones de la sociedad.

\section{Buenos Aires en los años '20}

Los años'20 fueron una época de transformaciones diversas y decisivas para Buenos Aires. El espectacular crecimiento que venía registrándose desde comienzos del siglo comenzaba a decantar y antes que ese proceso en sí lo que más llamaba la atención eran las consecuencias que ese crecimiento producía.

El desarrollo económico de la ciudad era sostenido. El puerto, el ferrocarril, las industrias urbanas - ubicadas principalmente en la zona sur-pero también un sin fin de talleres, comercios y oficinas de servicio dotaban a la ciudad de una incesante actividad productiva. La zona en la que se concentraban las actividades comerciales y administrativas extendió $\mathrm{su}$ radio, los edificios se multiplicaron $\mathrm{y}$ embellecieron.

Por otro lado, si bien no hay datos censales para la década del '20, puede estimarse el fortísimo crecimiento demográfico experimentado por esos años al comparar los datos de 1914, con 1 millón y medio de habitantes aproximadamente y los de $1936^{4}$ con casi 2 millones y medio de habitantes. Al aumento de la población correspondió una extensión de la planta urbana misma: poco a poco los terrenos que se encontraban más alejados del casco tradicional de la ciudad fueron cambiando su fisonomía, urbanizándose, incorporando

Prácticas y valores en el proceso de popularización del futbol. Buenos Aires 1900-1910,en revista Entrepasados, Buenos Aires. No12, ppios. 1997, sobre la difusión de la práctica del futbol. Para otros contextos, GOMES, Tiago de Melo. Um espelho no palco. Identidades sociais e massificacao da cultura no teatro de revistados anos 1920. São Paulo: Campinas/Unicamp, 2004 y FRITZSCHE, Peter. Berlin 1900. Prensa, lectores y vida moderna. Buenos Aires: Siglo XXI, 2008.

4 Para ambas fechas, 1914 y 1936 sí se cuenta con datos censales oficiales. 
servicios y dando lugar a la emergencia de lo que comenzó a identificarse como "barrios".

Una serie de procesos sociales y culturales incidieron también tanto en la creación como en las características que estos barrios asumieron: en ellos comenzaron a delinearse nuevas identidades, pertenencias y formas de sociabilidad. En efecto, el crecimiento cuantitativo iba de la mano de mudanzas diversas que modelaban nuevos rasgos en el perfil social de la ciudad. Poco a poco emergía una sociedad dinámica y marcada por una tendencia a la movilidad social. Esto creaba nuevas y diversas situaciones ocupacionales que ampliaban hacia arriba y hacia los costados los lugares de la escala social. Cruzado con esta diversidad comenzó a darse también un proceso de "argentinización", tanto demográfica, dada por el paso mismo de una generación inmigrante a otra ya nacida en el país, como cultural en la medida en que la alfabetización y la escolaridad seguían extendiéndose entre las familias extranjeras y criollas (GUTIERREZ; ROMERO, 1989, p. 5-20).

Por otro lado, barrios y centro se conectaban a través de las calles y las avenidas que se iban abriendo; la extensión de las líneas de tranvías, de subterráneos y la difusión de nuevas líneas de colectivos fueron, a su vez, fundamentales para permitir el transporte de una zona a otra de la ciudad. Para quienes podían acceder, el automóvil o el taxi también se convirtieron en los modos más prácticos de llegar desde los barrios al centro (GARCIA HERAS, 1994).

Esta ebullición, provocada por los cambios materiales, sociales y culturales, implicó, en definitiva, la constitución de una sociedad de mezcla, en la cual se cruzaban los "mil sutiles hilos de la cultura", tal como lo ha señalado el historiador José Luis Romero (ROMERO, 2000) Y esos mil sutiles hilos encontraban su materialidad en los tranvías, las avenidas, los cables y las nubes de humo que atravesaban la ciudad y unían realidades sociales y universos culturales heterogéneos: los barrios acomodados de la zona norte con los obreros de la zona sur, los conventillos habitados aún por miles de inmigrantes con los petit hotel de la elite criolla, las luces de los teatros y cabarets del centro con los bosques de Palermo, ${ }^{5}$ las vanguardias de los cafés literarios con los mitos del arrabal y los compadritos. Y también en los personajes y productos que circulaban por la ciudad entretejiendo universos culturales diversos: la "milonguita" que abandona el suburbio para intentar triunfar en los cabaret, el político que recorría los barrios suburbanos para asegurarse los votos, el niño de la elite que frecuentaba los prostíbulos de las orillas, el diario Crítica ${ }^{6}$ que se vendía tanto en los barrios como en el centro y la calle Corrientes, la cual parecía funcionar como un "terreno neutral" -según Romero- para la integración, la tensión y la mezcla de los diversos universos culturales que componían el tejido social porteño. En efecto, si Buenos Aires logra expresar mejor que otras urbes latinoamericanas la idea de una cultura de mezcla, lo cierto es que esa mezcla fue en parte consecuencia de la labilidad de las fronteras que separaban lo que se presentaba como diverso y que permitió, a su vez, sostener un proceso de movilidad geográfica, social y cultural.

En conjunto, estas transformaciones configuraron una experiencia social que se tradujo en diversos productos, prácticas, representaciones, sujetos, identidades y conflictos propios de la vida urbana. En otras palabras, en variadas experiencias particulares. Lo que en este trabajo se sostiene, entonces, es que el teatro de género chico constituyó una de esas experiencias particulares: en primer lugar, porque en una ciudad de 2 millones de habitantes, los

5 Parques en el que solían pasear las clases más acomodadas de la ciudad.

6 Crítica, iniciado en 1914, significó la llegada del periodismo moderno a la Argentina: por el tipo de tecnología utilizada, el formato, el modo de enunciar, la importancia que adquieren los avisos publicitarios, etc. SAITTA, Sylvia. Regueros de Tinta: el diario Crítica en la década de 1920. Buenos Aires: Sudamericana, 1998. 
aproximadamente 6 millones de entradas vendidas para los espectáculos teatrales en el año $1926^{7}$ permiten indicar el grado de involucramiento -de una u otra manera- de la sociedad con la actividad teatral. En segundo lugar, porque dadas las características que exploraremos en el apartado siguiente, el teatro de género chico dependió y fue parte de los procesos de cambio que ocurrían en la sociedad de esos años.

\section{El mundo del teatro en la calle Corrientes}

Desde los años del Centenario, y particularmente, luego de la finalización de la Primera Guerra Mundial, diversas actividades y espacios vinculados a la recreación, los espectáculos y la vida de la bohemia fueron concentrándose en una zona particular de Buenos Aires: a lo largo de las primeras veinte cuadras de la calle Corrientes -que nacía en la zona sureste de la ciudad, cerca del río, y corría hacia el oeste- y en las manzanas aledañas se entremezclaban teatros de diverso tipo y capacidad, con otras salas dedicadas a proyectar las primeras cintas de cine y con otras que ofrecían espectáculos de varietés (números musicales, de baile, de circo, de ilusionismo, etc). Junto a las salas se multiplicaban los cafés, confiterías y restaurantes que convocaban a intelectuales, políticos $\mathrm{y}$ artistas. $\mathrm{Y}$ en las manzanas laterales a Corrientes, comenzaban también a aparecer los renovados cabarets (CAMPODÓNICO; LOZANO, 2000). En conjunto, esta zona con eje en la calle Corrientes pasó a nombrarse, sin serlo geográficamente, como el "centro" de la ciudad.

De todas esas posibilidades de entretenimiento que se ofrecían, los espectáculos de teatro -y en particular los llamados de género chico- ocupaban un lugar distintivo. En primer lugar, la actividad teatral venía experimentando un crecimiento notable: en 1911 en el centro existían 21 salas,

7 El dato está tomado de la Estadística Municipal, de 1926. en 1925 llegaban a 32 y en 1928 ya había más de 40. El Teatro Nacional, el Opera, el mencionado teatro Porteño -propiedad de Augusto Alvarez- el Maipo, el Florida son algunos de los tantos nombres de salas que brillaron en los años '20. Pero además de estas salas céntricas, en los barrios también comenzaron a levantarse teatros y espacios diversos para las representaciones teatrales. Las diferencias entre los teatros del centro y los de los barrios corrían en varios sentidos: la capacidad, las comodidades ofrecidas, la popularidad de los artistas que allí actuaban, todo lo cual también repercutía en el precio de las entradas que se cobraba. No obstante, algunos barrios -sobre todo los que crecían a ritmo sostenido como Boedo, Villa Crespo, Belgrano-contaban con importantes salas en las cuales se realizaban temporadas a cargo de figuras destacadas.

En promedio, las salas del centro tenían una capacidad para 700 espectadores y su espacio se organizaba en distintas ubicaciones (platea, palcos bajos, y altos, tertulias y paraíso). Algunos tenían escenarios amplios para montar varios decoradoy telones y contaban conmodernos sistemas de iluminación y ventilación. Los camarines, halls de entradas, salas de estar, tapizados y cortinados, y demás instalaciones de las salas -pese a las quejas de Chevalier- se fueron mejorando a medida que el crecimiento de la actividad teatral así lo exigía.

Los precios de las entradas variaban, según el teatro y el tipo de espectáculo ofrecido e iban desde los $\$ 0.30$, cobrados en los teatros más pequeños y en general para proyecciones de cine, hasta los $\$ 2.5$ que llegaban a cobrarse en los teatros más importantes de la calle Corrientes. En sí, los precios más económicos no significaban un costo excesivo si se los compara, por ejemplo, con los precios de algunos alimentos básicos $(0,60$ por un kilo de pan, $\$ 0,20$ el litro de leche, $\$ 0,50$ el kilo de fideos y $\$ 0,60$ el kilo de carne $)^{8}$ o en relación al

8 Datos extraídos del Boletín Mensual de Estadística Municipal de la Ciudad de Buenos Aires. 1925. 
salario ofrecido para una mucama ( $\$ 70$ mensuales) en los avisos clasificados de un diario de 1926.

\section{Funcionamiento por secciones}

Tanto las salas del centro como las de los barrios abrían sus puertas todos los días, desde las 18:00 hs y hasta la medianoche y ofrecían funciones por secciones. Habitualmente, los teatros tenían hasta 4 funciones diarias, sucesivas, que permitía combinar representaciones teatrales con otras musicales y hasta circenses. Algunos teatros ponían restricciones para la admisión del público y anunciaban sus espectáculos como "no aptos para señoritas". Pero el grueso de la cartelera lo ocupaban obras cortas, con tramas sencillas, con personajes y situaciones típicamente urbanas, a veces presentadas de manera caricaturesca, preferentemente en tono de comedias aunque también había dramas, acompañados de música en vivo. Esas eran las obras consideradas como de género chico.

El funcionamiento por secciones permitía que los teatros diversificaran sus ofertas de entretenimiento para que el público pudiera adecuar sus preferencias a su disponibilidad económica y de tiempo. Por un lado porque las entradas se compraban para cada función: quien quisiera podía comprar para una sola función o para varias. Por otro lado, dado que las obras eran relativamente breves, cada presentación no llevaba mucho más de una hora: quienes asistían no necesitaban disponer de toda la tarde o toda la noche para pasar un momento de distracción y ocio. En una calle Corrientes donde circulaban día a día miles de personas la flexibilidad que ofrecía el sistema por secciones era una oportunidad para diversificar ofertas y apuntar a una mayor cantidad de público.

\section{Compañias y actores}

A medida que las salas y las funciones se multiplicaban, también aumentaba el número de gente vinculada a la actividad teatral. Los artistas se agrupaban en compañías, las cuales estaban a cargo de un empresario que podía ser también el actor principal de la agrupación e incluso el dueño del teatro en el cual la compañía realizara la temporada. Internamente, la compañía se organizaba partir de una jerarquía asociada a roles prefijados tales como primer actor o primera figura, galán joven, dama joven, actores de caracterización, etc. ${ }^{9}$ Un relevamiento organizada por una publicación de la época, el Anuario Teatral Argentino, indicaba que para 1925 era posible identificar y caracterizar a unas 118 compañías (según su nombre, director, género al que se dedicaba, cantidad de artistas, etc). El número de integrantes variaba de entre 10 y 40 artistas. Si se multiplica la cantidad de compañías por un número variable de artistas por compañía (25 en promedio) el resultado da una idea del número de artistas que trabajan en los escenarios porteños: cerca de 3000 .

Además de los actores y actrices, la compañía podía contar también -aunque con roles más secundarios- con coristas, bailarines y músicos en algunos casos. $Y$ junto a ellos trabajaban técnicos, maquinistas, iluminadores, acomodadores y otros tantos oficios indispensables para que la función pueda representarse. La puesta de las obras y la coordinación de las tares estaba a cargo de uno o varios directores, tal el caso de los mencionados Ivo Pelay y Manuel Romero. Alrededor de todos ellos se movía el mundo de la farándula de la época: los autores, los empresarios, pero principalmente los actores y las actrices eran personalidades conocidas, queridas y de las cuales se hablaba en diarios y revistas.

9 De esos roles dependía el sueldo que se cobraba. No obstante, la compañía en sí misma era un espacio para hacer carrera. Quienes ingresaban con un papel muy discreto podían ascender y conseguir un rol más destacado. 
Mundo del teatro, mundo del trabajo?: empresarios y artistas

Visto desde otra perspectiva, el mundo del teatro funcionaba con una lógica comercial: los dueños de las salas eran empresarios que organizaban, contrataban $\mathrm{u}$ ofrecían las instalaciones para que las compañías realicen la temporada. Su ganancia provenía básicamente de la venta de entradas o del arrendamiento de la sala. Si bien solían denunciar -a través de su propia entidad corporativa, la Sociedad de Empresarios Teatrales- los riesgos del negocio del espectáculo y los altos impuestos que pagaban, las estadísticas fiscales de la Municipalidad sobre lo recaudado en los teatros indica que aún con riesgos el negocio del espectáculo era rentable.

La contraparte de esto es el hecho de que los artistas eran trabajadores en el sentido de que estaban enrolados en una compañía, que dependían de un salario (pautado a través de distintos tipos de contrato) y que debían cumplir con una serie de condiciones laborales. En un contexto particular en el cual la actividad teatral se extendía pero los empresarios querían ganar cada vez más y en una coyuntura de extrema conflictividad social emergieron una serie de conflictos sindicales y políticos que pusieron en tensión al mundo del teatro.

En efecto, en 1919 y 1921 -años de intensa movilización y conflictividad social en Buenos Aires- las actividades teatrales quedaron paralizadas por sendas huelgas declaradas en el primer caso por los actores y en el segundo movilizada fundamentalmente por la entidad gremial de los autores. Más allá de las reivindicaciones planteadas y los diversos sucesos acontecidos, ambos conflictos dieron cuenta de la importancia que las entidades gremiales de actores y autores tenían como instancias de organización y representatividad en el mundo del teatro y frente a la sociedad.
Incluso, desde el gremio de los autores se promovió la creación de una Federación de Gentes de Teatros, una entidad que buscaba nuclear a todos los oficios y profesiones artísticas (GONZALEZ VELASCO, 2009).

Los artistas también participaron del espacio político porteño. En 1926, pasada la etapa de conflictividad, se creó un partido político de alcance local llamado Gente de Teatro, que consiguió que su primer candidato, el conocido actor y empresario Florencio Parravicini, se consagrara concejal de la ciudad de Buenos Aires. La experiencia política de los artistas -por diversas razonesfue efímera pero alcanza para mostrar la inserción que el mundo del teatro tenía en la sociedad y en la política porteña. En las elecciones municipales solían presentarse muchos pequeños y ocasionales partidos, pero en general los resultados siempre favorecían a las agrupaciones más grandes y con mayor proyección nacional: radicales y socialistas. Gente de Teatro, pese a su precaria y fugaz organización, logró sumarse momentáneamente a estos elencos políticos, y en gran medida este resultado positivo remite a la popularidad -ganada en los escenarios de teatro -y no en púlpitos o mitines político - de quienes integraban la lista.

Comosea, la actividad teatral siempre fue discutida en el Concejo Deliberante -la instancia del gobierno municipal- más allá de la llegada de la representación de los artistas dada la importancia pública que la misma tenía: la seguridad de los espectáculos, considerando la cantidad de gente que circulaba por ellos, y los impuestos a cobrar, dadas las ganancias de los empresarios eran los dos principales problemas sobre los que la municipalidad se expedía. Si bien existía una Comisión encargada de aplicar censura en determinados casos, prácticamente no se encuentran acontecimientos de este tipo. 


\section{El teatro en el mundo editorial}

Durantelosaños'20el mercadoeditorial de la ciudad experimentaba también una etapa de auge: por diversas razones -entre las cuales se cuenta los elevados índices de alfabetización de la ciudaden los años '20 se publicaban decenas de diarios y revistas de todo tipo, además de colecciones de libros, a bajo costo y con una amplia difusión (ROMERO, 2000). La actividad teatral encontró también su nicho y requirió que los periódicos contaran con secciones y periodistas especializados en temas teatrales. Día a día, en la columna de espectáculos se informaba sobre los estrenos programas, se publicaban las críticas a las obras en cartel y se comentaba la actualidad del mundo artístico.

Además, el interés de la sociedad por el teatro y las favorables condiciones editoriales también significaron la circulación de decenas de revistas especializadas, algunas de las cuales se dedicaban no sólo a comentar y discutir cuestiones de la actividad teatral sino también a publicar semanalmente los libretos de las obras estrenadas. Algunos de estos proyectos tuvieron una vida efímera, pero otros fueron más exitosos. Vistos en conjunto indican que, por ejemplo, entre 1918 y 1923 se editaron simultáneamente al menos 10 revistas de teatro, repartiéndose su aparición a lo largo de la semana. Las revistas Bambalinas y La Escena, ambas de aparición semanal y sistemática entre 1918 y comienzos de los '30, fueron dos de las más importantes. Juntas, editaron cerca de 1800 obras, todas de autores nacionales y uruguayos, y casi todas estrenadas en los años' $20 .{ }^{10}$

Esa cantidad de obras publicadas da cuenta, en definitiva de la abundante producción dramática de los años '20 y del importante número de autores que trabajan

10 Bambalinas se publicó entre 1919 y 1934, según el catálogo editó 921 títulos. La revista La Escena, se publicó entre 1918-1933, editó 797 títulos. Sobre las revistas teatrales, MAZZIOTTI, Nora.. Bambalinas: el auge de una modalidad teatral periodística, en ARMUS, Diego (comp) Mundo urbano... (Op. Clt). para dotar a una demandante cartelera. La entidad gremial de los autores, hacia 1920, contaba con más de 200 socios. Algunos trabajaban a pedido, y escribían sus obras según expresas indicaciones de actores o empresarios. Otros, más reconocidos, ofrecían sus obras a quienes ellos quisieran. Los contratos entre autores y empresarios variaban, pero básicamente se esperaba que el autor cobrara "derechos de autor", un porcentaje ya estipulado a partir de la venta de las entradas de las funciones en las que se representara la obra en cuestión. Esta tramitación era controlada por la entidad gremial de los autores.

\section{La ciudad en el género chico}

¿De qué se trataban estas obras? La consideración de los títulos de las obras editadas en las revistas Bambalinas y La Escena permite aseverar la centralidad que la temática urbana tenía en el conjunto de las obras. La relación con su propio contexto histórico es otro aspecto definitorio: son muy pocas las obras de carácter histórico, prácticamente todas las obras se inician con la indicación "época actual".

La ciudad se despliega en las obras a través de múltiples entrada y esto permite dar cuenta de distintas experiencias de la vida urbana: los espacios de la ciudad, la política, las relaciones domésticas, de género, étnicas, o el problema de la vida urbana fueron algunos de los temas a partir de los cuales el teatro mostró la ciudad y la vida cotidiana. El teatro además lo mostró de manera polifónica, dando cuenta de las distintas miradas y voces que sobre tal o cual cuestión circulaban. A su vez, considerando la diversidad de la platea que asistía las funciones, probablemente hayan funcionado de manera polisémica, facilitando que esas imágenes sean significadas de distintas maneras.

Así, por ejemplo, muchas de las obras tomaron como título el nombre de algún barrio: "Nueva Pompeya"; "Los zorzales de Pompeya"; "En un rincón de la Boca"; "Palermo chico", "Allá cerca e la Floresta", 
"El barrio de Balvanera". En algunos casos, el barrio sólo funciona como escenografía para situar el argumento de la obra. En otros, las características particulares del barrio condicionan el desarrollo de la obra. A su vez, los modos de presentar los barrios de la ciudad variaban de una obra a otra y según de qué barrios se hablara: en algunos casos, los barrios -sobre todo los de la zona sur- eran asociados a la mala vida aunque también -dado que eran la zona en la que se ubicaban la mayoría de las fábricas y el puerto- a la vida de los trabajadores. En otras obras, se hablaba de los barrios en tono de nostalgia, aludiendo a situaciones que ya habían desaparecido y esto mismo cargaba a los barrios de valores a defender frente al avance de la vida moderna. Para mediados de los años '30, muchas de las características asignadas a los barrios ya habían decantado en imágenes más compartidas sobre lo que los barrios eran. La obra "La canción de los barrios", sintetiza ese punto de llegada, al presentar en distintos cuadros las principales características de cada una de las zonas porteñas reconocidas como barrios.

El teatro también habló de la ciudad a través de la mención, en los títulos, de los nombres de las calles que, por distintas razones, eran significativas: Boedo y San Juan, esquina asociada a uno de los clubes de futbol más importantes de los años ' 20 y '30 (San Lorenzo de Almagro); Corrientes y Esmeralda, Corrientes 3-4-8 $\left(2^{\circ}\right)$, La Calle Florida, calles éstas asociadas a la diversión, los teatros y los cabarets. También a través de los nombres de sus principales teatros y cabarets: Las chicas del Maipo, Al Politeama Chofe, La pebeta del Ba-TaClan, La bailarina del Empire Theatre, La muchachada del Pigall, Montmartre, Armenonville. ${ }^{11}$

La vida moderna, como aspecto clave y representativo de la ciudad estuvo presente, como modo de predicar sobre la vida urbana: así, en distintas obras se hablaba -a veces de manera central, a veces

11 El Maipo, Politeama, Ba-Ta-Clan y el Empire Theatre eran algunos de los teatros más importantes de la época; Pigall, Montmartre, Armenonville eran los cabarets más famosos. de manera accesoria- de la importancia que determinados productos considerados "modernos" tenían en la vida cotidiana. En la obrita "Los hinchas- Triunvirato Footbal club"' y en "Hoy transmite RATTI-CULTURA", la radio era un elemento fundamental para el desarrollo del argumento de la obra. Por su parte, en la obrita "La escuela de los audaces", el uso de los teléfonos también era un elemento de relevancia. Y en "Mi familia tiene un Ford" el uso del automóvil es, de hecho, el tema central sobre el cual trata la obra. También en relación al uso de estos productos, las obras combinan una mirada que critica su difusión (mostrando cómo los automóviles generan, por ejemplo, accidentes) pero que al mismo tiempo ratifica la difusión que los mismos tenían en la vida cotidiana de los porteños.

Por otro lado, al situar a las obras en su contexto, es decir, pensadas como artefactos que describen y construyen imágenes de la ciudad, que son vistas por cientos y cientos de personas cada día, y luego leídas en los ejemplares de las revistas, la posibilidad de que cumplan alguna otra función además de la divertir a un amplio público se presenta como una veta de análisis a explorar. En este punto, la explicación de Peter Fritzsche sobre la función que la prensa cumplía en Berlín para $1900,{ }^{12}$ es por demás sugerente. También para un contexto de rápidos y profundos cambios urbanos, Fritzsche muestra cómo los periódicos de circulación masiva crearon una "ciudad textual", que interactuaba con la "ciudad de cemento". En una época de cambios demográficos que implicaron la llegada de muchos nuevos habitantes y la reorganización de los espacios urbanos, los diarios eran la llave para poder conocer la ciudad, recorrerla, disfrutarla y sortear sus peligros. De ahí que el mencionado autor considere que la prensa funcionaba como una "enciclopedia urbana".

12 FRITZSCHE, Peter. Berlin 1900... Op. Cit 
Desde esta perspectiva, entonces, es posible sostener que, si el género chico era un teatro predominante urbano, se dirigía a un público masivo y funcionaba en diálogo permanente con su propio contexto, estableciendo una relación de ida y vuelta entre "la ciudad teatralizada" y "la ciudad de cemento", es posible pensarlo también como una "enciclopedia urbana". Puesto en el contexto de una ciudad que crecía a ritmo sostenido y en una sociedad caracterizada por el cambio y mezcla, estas obras pudieron funcionar como guías para habitar y vivir esa ciudad, en la medida en que la mostraban, la explicaban, la discutían y la recreaban desde distintos ángulos. En diálogo con la prensa, la literatura y el tango, el teatro también construyó sentidos sobre la ciudad y la vida urbana.

\section{Buenos Aires, Gente de Teatro}

Al día siguiente del estreno Chevalier, la crónica teatral de un importante diario de la ciudad comentaba: “Un espectáculo variado $y$ entretenido $y$ en el que abundan notas de buen gusto. 'Chevalier revista'[título de la revista en la que actuaba Chevalier] atraerá público muchas noches. Será una compensación merecida por el esfuerzo realizado por los dirigentes del Porteño". ${ }^{13} \mathrm{Y}$ así fue. Su actuación fue aplaudida durante toda la temporada $y$ durante varios meses, el Porteño funcionó prácticamente a pleno en cada una de las secciones en las que actuaba el francés. $\mathrm{Su}$ paso por la capital permitió, tal como suponía Álvarez, consolidar la revista de corte francés en los escenarios porteños. ${ }^{14}$

La anécdota de Chevalier y de Alvarez deja huellas para dar cuenta de la importancia del fenómeno teatral pero también permite adentrarse en el análisis

13 Maurice Chevalier se presentó anoche en el Porteño. La Razón, 27 de mayo 1925.

14 El Boletín del Círculo Argentino de Autores, entidad gremial de los autores de teatro publicaba mensualmente un listado con los títulos y géneros de las obras estrenadas: a partir de 1926 más de la mitad de los estrenos corresponden a revistas. de la sociedad y sus diversas experiencias. La configuración del centro como paisaje urbano vinculado a los entretenimientos, por ejemplo, fue resultado del cruce entre una cierta disponibilidad de recursos y de tiempo para gastar en ocio por parte de los diferentes sectores sociales y el interés de empresarios de responder y aprovechar esa disposición. Un mercado de entretenimientos se configuraba entre las demandas (y disponibilidades) de la sociedad y la oferta de los empresarios: asistir al teatro era una práctica que podría vincularse, entre otras cosas, al consumo. Como hemos indicado en otro trabajo, ${ }^{15}$ la concentración de actividades recreativas en esta zona combinada con las características de su funcionamiento explica en parte la emergencia de un mercado de entretenimientos. A su vez, la configuración de este mercado remite a los procesos de transformaciones de la ciudad y la sociedad mencionados. Por otro lado, los años '20 fueron, en particular, una etapa de mayorestabilidadeconómicaencomparación con los años inmediatos a la finalización de la guerra: la relación de los precios y los salarios favoreció a los consumidores y las familias, fundamentalmente las de los sectores medios, dispusieron de ciertos márgenes económicos y más disponibilidad de tiempo para consumir bienes y prácticas vinculadas al ocio o la recreación. Por otro lado, el progreso material de la ciudad, su expansión física, la emergencia de los barrios y el desarrollo de la infraestructura y los transportes, al tiempo que reordenó los espacios urbanos asociados a la residencia, el trabajo y la recreación, facilitó la circulación y el aprovechamiento del tiempo. La prensa y diversas publicaciones, también fenómenos propios de la vida urbana, informaban a diario sobre la cartelera de teatros y cines, sus horarios, direcciones, etc, lo cual también alentaba y facilitaba el acercamiento al centro (GUTIÉRREZ; ROMERO, 1989).

15 GONZÁLEZ VELASCO, Carolina. Una pandilla de truhanes y un cándido público: el negocio de los espectáculos teatrales, Buenos Aires, 1920. Revista Nuevos Mundos Mundo Nuevo (en prensa). 
Visto desde otra perspectiva, el negocio de los espectáculos se apoyaba en un conjunto de actores, autores, músicos, maquinistas y otros tantos oficios que eran en definitiva quienes día a día daban vida a las funciones. Para todos ellos el mundo del teatro era, entre otras cosas, su ámbito de trabajo y en función deél-y dela experiencia misma del trabajo- configuraron diversas identidades colectivas. La "compañía" era la instancia de organización del trabajo de los artistas: los actores eran actores de una compañía, por ejemplo. Pero en el contexto de conflictividad y movilización que sacudió a toda la sociedad porteña en los años inmediatamente posteriores a la primera guerra mundial, ese modo de definir identidades y pertenencias fue puesto en cuestión y redefinido.

La instancia en donde más claramente queda evidenciada la relación entre el mundo del teatro y la sociedad porteña, el punto de encuentro, son las obras que llenaban la cartelera de los teatros: escritas por autores, representadas por actores con la ayuda de otros oficios, elegidas y modificadas por los empresarios, vistas y comentadas por el público, promocionadas y criticadas por la prensa y finalmente leídas por un público que, más allá de haber ido o no al teatro, elegía leer ( $\mathrm{y}$ tal vez representar en los cuadros filodramáticos) los libretos. Todos los integrantes del mundo del teatro, incluido en este caso el público, de un modo u otro establecían algún tipo de relación y de apropiación con las obras. En este sentido, las obras concentraban ese encuentro entre los múltiples participantes del mundo del teatro.

A su vez las obras, dada la diversidad temática planteada como también la diversidad de voces que es posible reconstruir sobre cada uno de esos temas, expresan claramente a esa sociedad de mezcla, atravesada por procesos de movilidad y transformación.

$\mathrm{Si}$, tal como lo han hecho muchos estudios del teatro, el foco del análisis se apoya en los aspectos estéticos y valorativos en relación a la evolución de la dramaturgia o en aquellos de crítica y denuncia por el carácter comercial de los espectáculos, el mundo social del teatro -con sus actores, sus conflictos, sus prácticas y representaciones, sus modos de funcionamiento- parece quedar sólo como trasfondo sin preguntas que lo problematicen. Desde nuestra perspectiva, es a través de las herramientas de la historia con las cuales es posible ampliar la lente para indagar sobre la vida teatral porteña de los años '20.

\section{Referências bibliográficas}

CAMPODÓNICO, Raul; GIL LOZANO, Fernanda. Milonguitas en-cintas. La mujer, el tango y el cine. En GIL LOZANO, Fernanda; PITA, Valeria ; GABRIELA, María. Historia de las mujeres en Argentina. Buenos Aires: Taurus, 2000.

FRITZSCHE, Peter. Berlin 1900. Prensa, lectores y vida moderna. Buenos Aires: Siglo XXI, 2008.

FRYDEMBERG, Julio. Prácticas y valores en el proceso de popularización del futbol. Buenos Aires 1900-1910, en revista Entrepasados, Buenos Aires. N ${ }^{\circ} 12$, ppios. 1997

GARCIA HERAS, Raul. Transportes, negocios y política. La compañía Anglo Argentina de Tranvías. 1876-1981. Buenos Aires: Sudamericana, 1994

GOMES, Tiago de Melo. Um espelho no palco. Identidades sociais e massificação da cultura no teatro de revistados anos 1920. São Paulo: Campinas/Unicamp, 2004.

GONZALEZ VELASCO, Carolina Gente de Teatro: género chico y sociedad. Buenos Aires, en los años '20. Buenos Aires: Siglo XXI. (en prensa)

Una pandilla de truhanes y un cándido público: el negocio de los espectáculos teatrales, Buenos Aires, 1920. Revista Nuevos Mundos Mundo Nuevo (en prensa)

Pierrot ha dejado su traje y enarbola la bandera roja que tan mal le sienta. Conflictos gremiales en el mundo del teatro porteño, 1919-1921 en BERTONI 
Lilia Ana y PRIVITELLIO, Luciano de (comp) Conflictos en democracia. La política en Buenos Aires 1850-1950. Buenos Aires: Siglo XXI, 2009.

GUTIERREZ, Leandro; ROMERO Luis Alberto. Sociedades Barriales, Bibliotecas populares y cultura de los sectores populares: Buenos Aires, 1920-1945. Desarrollo Económico. Vol XXIX, N¹13, 1989.

KARUSH, Matthew "The Melodramatic Nation: Integration and Polarization in the Argentine Cinema of the 1930s"en Hispanic American Historical Review, 2007.

MANFREDI, Alberto. Augusto Álvarez, pionero de la cinematografía argentina. Buenos Aires, 1989.

MAZZIOTTI, Nora. Bambalinas: el auge de una modalidad teatral periodística, en ARMUS, Diego (comp) Mundo urbano y cultura popular. Estudios de Historia Social Argentina (comp) Buenos Aires: Editorial Sudamericana: 1990.

ORDAZ, Luis. Historia del Teatro Argentino. Buenos Aires: Instituto Nacional del Teatro, 1999.

PELLETIERI, Osvaldo. (Director). Historia del Teatro Argentino. Vol II. Buenos Aires: Galerna, 2000.

PUJOL, Sergio. Valentino en Buenos Aires. Los años '20 y el espectáculo. Buenos Aires: Emecé, 1994.

ROMERO José Luis. La ciudad burguesa en ROMERO, Luis Alberto. ROMERO, José Luis. Buenos Aires. Historia de cuatro siglos. Buenos Aries, Altamira (2 ${ }^{\circ}$ ed), 2000.

ROMERO, Luis Alberto. Buenos Aires en la entreguerras: libros baratos y cultura de los sectores populares. ARMUS, Diego Mundo urbano y cultura popular. Estudios de Historia Social Argentina (comp). Buenos Aires: Editorial Sudamericana, 1990.

SAITTA, Sylvia. Regueros de Tinta: el diario Crítica en la década de 1920. Buenos Aires: Sudamericana, 1998.

SARLO, Beatriz. El Imperio de los Sentimientos. Buenos Aires: Catálogo Editora, 1985. 